\title{
Hypoxia and anoxia effects on alcohol dehydrogenase activity and hemoglobin content in Chironomus riparius Meigen, 1804
}

\author{
Valentina GRAZIOLI,${ }^{1,2}$ Bruno ROSSARO, ${ }^{1}$ Paolo PARENTI, ${ }^{3}$ Roberto GIACCHINI, ${ }^{3}$ Valeria LENCIONI ${ }^{*}$ \\ ${ }^{1}$ Department of Agri-food and Urban Systems Protection, University of Milan, Via Celoria 1, 20133 Milan; ${ }^{2}$ Section of Invertebrate \\ Zoology and Hydrobiology, MUSE-Science Museum, Corso del Lavoro e della Scienza 3, 38123 Trento; ${ }^{3}$ Department of Earth and \\ Environmental Sciences, University of Milan - Bicocca, Piazza della Scienza 1, 20126 Milano, Italy \\ *Corresponding author: valeria.lencioni@muse.it
}

\begin{abstract}
The metabolic effects of low oxygen content on alcohol-dehydrogenase (ADH) activity and hemoglobin (Hb) concentration were investigated in IV-instar larvae of Chironomus riparius (Diptera: Chironomidae) from an Italian stream. Two series of short-term (48 h) experiments were carried out: exposure to (1) progressive hypoxia (95 to 5\% of oxygen saturation) and (2) anoxia (at $<5 \%$ of oxygen saturation). In (1), Hb amount increased with increasing oxygen depletion up to a critical value of oxygenation (about $70 \%$ of oxygen saturation). Below this percentage, the Hb amount declined to values comparable with those present in the control. The respiration rate $(R)$ remained almost constant at oxygen saturation $>50 \%$ and decreased significantly only after 48 h of treatment $(=<5 \%$ of oxygen saturation) reaching values $<100 \mathrm{\mu molO}_{2} \mathrm{gAFDW}^{-1} \mathrm{~h}^{-1}$. ADH activity showed two phases of growth, within the first $14 \mathrm{~h}$ and over 18 h of exposure. Overall, we inferred that i) Hb might function as short-term oxygen storage, enabling animals to delay the onset of anaerobiosis; and ii) alcoholic fermentation co-occurs for a short time with aerobic respiration, becoming the prevalent metabolic pathway below $5 \%$ of oxygen saturation $\left(<1 \mathrm{mg} \mathrm{L}^{-1}\right)$. These considerations were supported also by results from anoxia exposure (2). In such condition, larvae were visibly stressed, becoming immobile after few minutes of incubation, and ADH reached higher values than in the hypoxia treatment $\left(2.03 \pm 0.15 \mathrm{UADH} \mathrm{mg} \mathrm{prot}^{-1}\right)$. Overall, this study showed a shift from aerobic to anaerobic activity in $\mathrm{C}$. riparius larvae exposed to poorly oxygenated water with an associated alteration of ADH activity and the Hb amount. Such metabolites might be valid candidate biomarkers for the environmental monitoring of running waters.
\end{abstract}

Key words: Freshwater insects; physical stress; experimental anoxia; anaerobic metabolism; enzyme activity; biomarkers.

Received: October 2015. Accepted: January 2016.

\section{INTRODUCTION}

Chironomids (Diptera: Chironomidae) are the most widely distributed insect family in freshwaters, inhabiting nearly all types of aquatic or semi-aquatic habitats including tree holes, bromeliads, rotting vegetation, soil, sewage and artificial containers (Armitage et al., 1995). Chironomids possess adaptations to a variety of environmental rigors (desiccation, anoxia, high temperature, freezing, eutrophication, chemical pollution), are ubiquitously distributed, easy to culture and with short life cycles (Ingersoll and Nelson, 1990; Choi and Roche, 2004). Thus they are an appropriate taxon to study the adaptive strategies necessary to survive environmental stress (Lencioni et al., 2008), to monitor water quality as bioindicators (Rosenberg, 2005) and to test toxicity of chemicals in ecotoxicological assays (Choi, 2004). Within the family Chironomidae, a wide range of tolerance to hypoxia/anoxia is displayed. In particular, the genus Chironomus (subfamily Chironominae, tribe Chironomini) is very tolerant towards low levels of dissolved oxygen (Frank, 1983; Hamburger et al., 1994; Marziali et al., 2006). Larvae inhabit the sediment of pools, profundal and sublittoral zones of lakes and river bottoms where they dwell in tubes and feed on detritus, encountering hypoxia or even anoxia (Jónasson, 1978; Sæther, 1979). Chironomus larvae are commonly known as bloodworms for the red colour of the body due to the hemoglobin $(\mathrm{Hb})$ synthesized in the body fat then secreted into the hemolymph where it accumulates (Bergtrom et al., 1976). This red respiratory pigment is rarely present in invertebrates and restricted to some taxa within insects and crustaceans (Ha and Choi, 2008).

From an evolutionary point of view, the presence of $\mathrm{Hb}$ in invertebrates represents an adaptation to hypoxic environmental conditions, since this pigment helps to sustain aerobic metabolism under low-oxygen conditions (Weber and Vinogradov, 2001). Hb plays a role in transporting but also storing oxygen during periods of rest and feeding (Hoback and Stanley, 2001). From an ecotoxicological point of view, animals possessing $\mathrm{Hb}$ are often considered candidate sentinel species for water quality monitoring (Osmulski and Leyko, 1986), and $\mathrm{Hb}$ have considerable potential as a sensitive biomarker for environmental monitoring and risk assessment (Frank, 1983; Zebe, 1991). Hb is the most abundant protein in Chironomus larvae (Choi 
et al., 2001), in which more than 30 cloned globin genes have been sequenced, and larvae synthesise up to $16 \mathrm{Hbs}$ and 12 globin polypeptides (Weber et al., 1985; Choi and Roche, 2004). Chironomus $\mathrm{Hb}$ has a very high affinity for oxygen that dissolves through the larval cuticle and saturates it. This process is favoured by the undulatory movements of the burrowing larvae to move water in their dwelling-tubes in the hypoxic mud (Weber, 1980; Lindegaard, 1995; Rossaro et al., 2007). The large capability of larvae of different species of Chironomus [e.g., C. plumosus (Linnaeus 1758)], C. anthracinus Zetterstedt 1860, C. riparius Meigen, 1804) to maintain at low oxygen concentrations an aerobic metabolism and consequently high levels of ATP, is associated to these extraordinary capability of their $\mathrm{Hb}$ to bind and store oxygen (Zebe, 1991; Penttinen and Holopainen, 1995).

Potentially, these high levels of ATP are maintained to support energy requirements for osmotic homeostasis, to filter-feed and resupply oxygen to the hemoglobin by flushing water through their burrows, to remove anaerobic endproducts including lactate and alanine accumulated under hypoxia (Scholz and Zerbst-Boroffka, 1998). There are evidences that as hypoxia becomes severe, $C$. riparius larvae switch to alcoholic fermentation, so that in long-lasting anaerobic conditions, ethanol is the sole end-product of the glycogen degradation, and it diffuses into surrounding water (Redecker and Zebe, 1988; Zebe, 1991). This anaerobic pathway is a feature apparently unique to insects (Wilps and Schöttler, 1980; Redecker and Zebe, 1988). The last reaction of the alcoholic fermentation (=oxidation of reduced nicotinamide adenine dinucleotide (NADH) coupled to reduction of acetaldehyde to ethanol) is catalyzed by the enzyme alcohol dehydrogenase (ADH).

The aim of this work was to study the effects of hypoxia and anoxia on the metabolism of $C$. riparius larvae through the measurement of $\mathrm{Hb}$ concentration in the hemolymph (associated to aerobic metabolism) and ADH enzymatic activity (associated to the anaerobic catabolism of carbohydrates). Although molecular and biochemical biomarkers have been frequently studied in Chironomus spp. (Choi, 2004), the effects of low oxygen content on hemoglobin concentration coupled with alcohol dehydrogenase activity were not previously reported for a single species of Chironomus.

\section{METHODS}

\section{Animal collection and rearing}

Experiments were conducted under laboratory conditions on a wild population of $C$. riparius living in a small lowland stream, Rio Gola, in NE-Italy (Trentino region, $187 \mathrm{~m}$ asl, $46^{\circ} 02^{\prime} 20^{\prime \prime} \mathrm{N}, 11^{\circ} 07^{\prime} 17^{\prime \prime} \mathrm{E}$ ). Larvae (all instars) were collected in early March 2010. Point measurements of water temperature $\left(18.3^{\circ} \mathrm{C}\right)$, percent oxygen saturation (103\%), dissolved oxygen concentration (9.4 $\left.\mathrm{mg} \mathrm{L}^{-1}\right), \mathrm{pH}(8.0)$ and conductivity $\left(2.45 \mathrm{mS} \mathrm{cm}^{-1}\right)$ were recorded in the field with a multiparametric probe Hydrolab Quanta in the time period from 11.00-13.00 h. Water level was of 5-10 cm and current velocity of $70 \mathrm{~cm} \mathrm{sec}^{-1}$ recorded with an OTT propeller-flow meter. Granulometry was fine $(<5 \mathrm{~cm})$ and bottom was covered by algal mats (green algae and cyanobacteria) in the littoral zone.

The sampling site was located about $20 \mathrm{~m}$ upstream the confluence with the Adige River, few km downstream Trento city, in an area intensively planted with vineyards and apple-orchards.

In total, 509 larvae (154 belonging to II instar and 355 to III-IV-instar) were collected with a $30 \times 30 \mathrm{~cm}$ pond net $(100 \mu \mathrm{m}$ mesh size $)$ and transported to the laboratory in plastic bags within $1 \mathrm{~h}$ after sampling. Rearing was performed in a aerated $34 \mathrm{~L}$ aquarium, filled with dechlorinated tap water maintained at $20 \pm 2^{\circ} \mathrm{C}$ by a refrigerator TECO TR15, with a natural photoperiod. A $5 \mathrm{~cm}$-layer of natural substrate was placed on the bottom of the aquarium. The substrate consisted of stream mud dried in an oven at $60^{\circ} \mathrm{C}$ for $48 \mathrm{~h}$, sieved on $250 \mu \mathrm{m}$ mesh and sterilized by UV radiation with a UV/White light transilluminator ${ }^{\circledR} \mathrm{TFP}-\mathrm{M} / \mathrm{WL}$ for $30 \mathrm{~min}$. Adult midges were prevented to escape using wooden cages covered with 0.5 $\mathrm{mm}$ mesh size nylon net. Larvae were fed with fish food flakes (Tetra-Min ${ }^{\mathbb{R}}$ ) every 2 days.

All the experiments were performed on IV-instar larvae (instar determination was performed using measurements of head capsule length according to McCauley, 1974) within three weeks after sampling.

\section{Experimental design: progressive hypoxia exposure and anoxia incubation}

One day before exposures, IV-instar larvae of C. riparius were randomly removed from the rearing aquarium and transferred, without mud, in $500 \mathrm{~mL}$ beaker (about 40 larvae per beaker), containing $200 \mathrm{~mL}$ of Hard Reconstituted Water (HRW) according to Lee et al. (2006). Larvae were kept for $24 \mathrm{~h}$ in a thermostatic room at $20^{\circ} \mathrm{C}$, with a 16L:8D photoperiod, at $95 \pm 0.2 \%$ of oxygen saturation without food nor mud supply to ensure empty guts (to avoid erroneously measuring oxygen consumption due to meal digestion). Three replicates of 1 larva each were used as control for each series of experiments; 111 replicates of 1 larva each were employed in progressive hypoxia (63) and anoxia (48) experiments. In both series of experiments, survival and biomarker concentration were detected after 0 (=control), 10, 14, 18, 24 and $48 \mathrm{~h}$. The choice of a single control at $\mathrm{t}=0$ was done according to Forcella et al. (2007) who highlighted as even after a hypoxia treatment, in normoxia enzyme activity and metabolite concentrations reached the normal values after few hours of recovery. 
Due to mortality or pupation of larvae in the two series of experiments, extra replicates were added (33 in all) to obtain a minimum number of replicates/h of 9 . A total of 144 larvae were treated in the two series of experiments.

The larvae that moved spontaneously or that moved only following a tactile stimulus were considered alive.

Before exposure, the wet weight of each larva was determined with an analytical balance $(0.0001 \mathrm{~g}$ of sensitivity). The mean weight of control larvae was $6.2 \pm 0.1 \mathrm{mg}$ in progressive hypoxia and $6.3 \pm 0.2 \mathrm{mg}$ in anoxia experiments.

As regards exposure to progressive hypoxia, 60 acclimatized larvae of similar weight $(6.4 \pm 0.2 \mathrm{mg})$ were each placed in one $10 \mathrm{~mL}-$ Biological Oxygen Demand (BOD) Schott Duran ${ }^{\circledR}$ glass bottle filled with HRW with $100 \%$ oxygen saturation ( $=9.2 \mathrm{mg} \mathrm{L}^{-1}$ ), without mud, closed taking care to avoid air bobbles. Bottles were immerged upsidedown into a glass beaker filled with tap water pre-heated at $20^{\circ} \mathrm{C}$, to ensure the fixing of the glass stopper. Due to mortality and pupation observed at 24 and $48 \mathrm{~h}$, extra replicates were added. At 10, 14 and 18 h, 12 replicates of 1 larva each were taken per each time of exposure; 9 of these replicates were used for the biomarker assays and 3 to measure oxygen consumption. At $24 \mathrm{~h}$, a total of 19 replicates of 1 living larva each were taken; 13 of these replicates were used for the biomarker assays and 6 to measure oxygen consumption. At $48 \mathrm{~h}, 18$ replicates of 1 living larva each were taken; 12 of these replicates were used for the biomarker assays and 6 to measure oxygen consumption.

As regards anoxia incubation, a 2 L- glass flask containing $1.5 \mathrm{~L}$ of HRW was flushed with pure $\mathrm{N}_{2}$ for 30 min to establish anoxic conditions. Flushing was continued for $30 \mathrm{~min}$ after transferring the larvae and the flask was sealed with Parafilm ${ }^{\circledR}$. Forty-five acclimatized larvae of similar weight $(6.2 \pm 0.4 \mathrm{mg})$ were introduced in the flask, subdivided in five $20 \mathrm{~mL}$-glass tubes (3 larvae/tube) without mud, each closed with a nylon gauze stopper (500 $\mathrm{mm}$ mesh size). Exposures were carried out for 10, 14, 18,24 and $48 \mathrm{~h}$ under constant temperature $\left(20 \pm 1^{\circ} \mathrm{C}\right)$. At each experimental time the dissolved oxygen concentration was monitored with a WTW Oxi 330i oxygen probe: only if the concentration was higher than $0.5 \mathrm{mg} \mathrm{L}^{-1}(<5 \%$ of oxygen saturation), $\mathrm{N}_{2}$ was gassed for some minutes. Due to mortality of three larvae at $48 \mathrm{~h}, 9$ extra replicates were added for a total of 54 larvae treated. At 10, 14, 18 $\mathrm{h}$ and $24 \mathrm{~h}$, a total of 9 replicates in all of 1 larva each were taken at each time of exposure for the biomarker assays. At 48 h, 15 replicates of 1 larva each were taken and used for the biomarker assays.

\section{Oxygen consumption measurement}

The oxygen consumption was measured using the closed-bottle method. Within the progressive hypoxia exposure experiments, on 3 replicate of each time series (6 at 24 and $48 \mathrm{~h}$ ), the initial and final dissolved oxygen con- centration in the experimental water was measured with Winkler's titration method (Winkler, 1888; Marsh and Manahan, 1999). The respiration rate was calculated using the following equation according to Lampert (1984), Hamburger and Dall (1990) and Brodersen et al. (2008):

Respiration rate $(\mathrm{R})\left(\mu \mathrm{mol} \mathrm{g} \mathrm{g}^{-1} \mathrm{~h}^{-1}\right)=$

$\left(\mathrm{O}_{2}-\mathrm{O}_{1}\right)$ AFDW $^{-1}\left(\mathrm{t}_{2}-\mathrm{t}_{1}\right)^{-1}$

where:

$\mathrm{O}_{2}(\mu \mathrm{mol})=$ dissolved oxygen concentration $\left(\mathrm{mg} \mathrm{L}^{-1}\right)$ at $\mathrm{t}_{2} \times 10 / 1000 \times 31.25$

$\mathrm{O}_{1}(\mu \mathrm{mol})=$ dissolved oxygen concentration $\left(\mathrm{mg} \mathrm{L}^{-1}\right)$ at $\mathrm{t}_{1} \times 10 / 1000 \times 31.25$

AFDW (Ash-Free Dry Weight) $(\mathrm{g})=0.114$ wet weight $\mathrm{t}_{2}-\mathrm{t}_{1=}$ time interval $(\mathrm{h})$.

\section{Hemoglobin and alcohol dehydrogenase assays}

In both series of experiments, biomarker concentration was detected after 0 (control), 10,14, 18, 24 and $48 \mathrm{~h}$ on survived larvae.

Hemolymph $\mathrm{Hb}$ concentration was measured in single alive larvae using the cyano-methemoglobin procedure (Tentori and Salvati, 1981; Int Panis et al., 1995). The larva was placed in $150 \mu \mathrm{L}$ of saline solution $(10 \mathrm{mM}$ potassium phosphate buffer $\mathrm{pH} 7.4$, containing $0.6 \%$ $\mathrm{NaCl}$ ) in a concave glass leaning on ice. Hemolymph was extracted from each larva by making an incision in the second thoracic segment with a sterilized scalpel, and letting the hemolymph flow for about ten min as described by Choi et al. (2000) and Choi and Roche (2004). The hemolymph and the buffer were drawn into a $200 \mathrm{~mL}$ micropipette, then frozen at $-20^{\circ} \mathrm{C}$. The remaining larval body was used for ADH detection (Choi et al., 2000).

The amount of $\mathrm{Hb}$ in the extracted hemolymph was evaluate using the Drabkin's solution, (Drabkin's reagent SIGMA), added with the appropriate amount of water and Brij 35 detergent (Tentori and Salvati, 1981; Choi and Roche, 2004).

In a glass vial (Hellma Special Optical glass) $300 \mu \mathrm{L}$ of Drabkin's solution and $30 \mu \mathrm{L}$ of sample were added. A vial containing $300 \mu \mathrm{L}$ of Drabkin's solution and $30 \mu \mathrm{L}$ af milliQ water was used as control. Absorbance was measured with the spectrophotometer and $\mathrm{Hb}$ concentration was calculated with the following equation:

$\frac{m g H b}{m L}=\frac{A_{540} \times d_{f} \times M W}{\varepsilon \times d}$

where:

$A_{540}=$ Absorbance at $540 \mathrm{~nm}$

$d_{f}=$ dilution factor $(=11)$

$M W=$ molecular weight of the hemoglobin monomer (14300 Da) 
$\varepsilon=$ extinction coefficient $\left(11 \mathrm{M}^{-1} \mathrm{~cm}^{-1}\right)$

$d=$ optical path $(=1 \mathrm{~cm})$.

Results were normalized on the sample total amount of proteins ( $\mathrm{mg} \mathrm{Hb} \mathrm{mg}$ prot $^{-1}$ ), determined with the UV extinction method (Layne, 1957) to avoid errors due to different rate of exit of hemolymph in the different larvae during the extraction phase.

Each larva, after hemolymph extraction, was homogenized at $4^{\circ} \mathrm{C}$ in a hypotonic buffer $(17 \mathrm{mM}$ HEPES-Tris, pH 7.4, $100 \mathrm{mM}$ mannitol), in a glass and Teflon PotterIKA-WERK Rw 14H, two time 10-strokes at $2000 \mathrm{rpm}$, separated by $2 \mathrm{~min}$ in ice (Forcella et al., 2007). The buffer volume $(\mathrm{mL})$ was calculated as 9 times the larval initial weight expressed as g (Forcella et al., 2004).

Crude homogenate was centrifuged at $4{ }^{\circ} \mathrm{C}$ for $30 \mathrm{~min}$ $(13,000 \mathrm{rpm})$. The resulting supernatant was stored at $20^{\circ} \mathrm{C}$ for further enzyme activity measurement. ADH was assayed according to Hanozet et al. (1976) at $340 \mathrm{~nm}$ with propionaldehyde.

The enzymatic activity was calculated with the following equation:

$\frac{U}{m g}=\frac{(A / \min ) \times V_{t}}{\varepsilon \times d \times V_{S}} \times(m g / m L)^{-1}$

where:

$\Delta A / \mathrm{min}=$ absorbance variation per minute

$V_{\mathrm{t}}=$ final volume of the reaction mix $(=1000 \mu \mathrm{L})$

$V_{\mathrm{s}}=$ volume of the sample added in the cuvette

$\varepsilon=$ extinction coefficient of the NADH $\left(6.3 \mathrm{mM}^{-1} \mathrm{~cm}^{-1}\right)$

$\mathrm{d}=$ optical path $(=1 \mathrm{~cm})$

$\mathrm{mg} \mathrm{mL} \mathrm{m}^{-1}=$ protein concentration of the sample.
All assays were performed in duplicate at $30^{\circ} \mathrm{C}$ using a Cary3 Spectrophotometer, recorded on personal computer, and analysed by the Cary WinUV application software for Windows XP.

Activity was expressed in international units (UADH) and referred to protein concentration (UADH mg prot ${ }^{-1}$ ). Total proteins were measured according to Bradford (1976) using bovine serum albumin as standard.

\section{Statistical analysis}

All values expressed are mean \pm SE. Means were compared by using the Mann-Whitney non-parametric U-test to detect significant $(\mathrm{P}<0.05)$ differences between treated and control groups. All analyses were run using STATISTICA $^{\circledR} 12.0$ computer package (StatSoft, 2012).

\section{RESULTS}

\section{Progressive hypoxia exposure}

Survival was $100 \%$ except after $24 \mathrm{~h}$ and $48 \mathrm{~h}$, when $20.8 \%$ and $25 \%$ of treated larvae respectively died or pupated. Larvae remained active for the first $24 \mathrm{~h}, 20 \%$ were undulating and $20 \%$ immobile after $48 \mathrm{~h}$. Oxygen in the medium (\% atm. saturation) was $95 \%$ in the control, $88.1 \%$ after $10 \mathrm{~h}, 81.7 \%$ after $14 \mathrm{~h}, 70.4 \%$ after $18 \mathrm{~h}$, $52.8 \%$ at $24 \mathrm{~h}$ and $4.4 \%$ after $48 \mathrm{~h}$ of treatment.

Fig. 1 shows the trend of $\mathrm{Hb}$ concentration and $\mathrm{ADH}$ activity in relation to progressive decrease in oxygen in the medium ( $\% \mathrm{~atm}$. saturation) with increasing treatment duration. The first significant increase in $\mathrm{Hb}$ was observed after $14 \mathrm{~h}$ of exposure $(\mathrm{P}=0.04)$, reaching a maximum after $18 \mathrm{~h}\left(0.663 \pm 0.032 \mathrm{mgHb} \mathrm{mg} \operatorname{prot}^{-1}, \mathrm{P}=0.01\right)$. Over

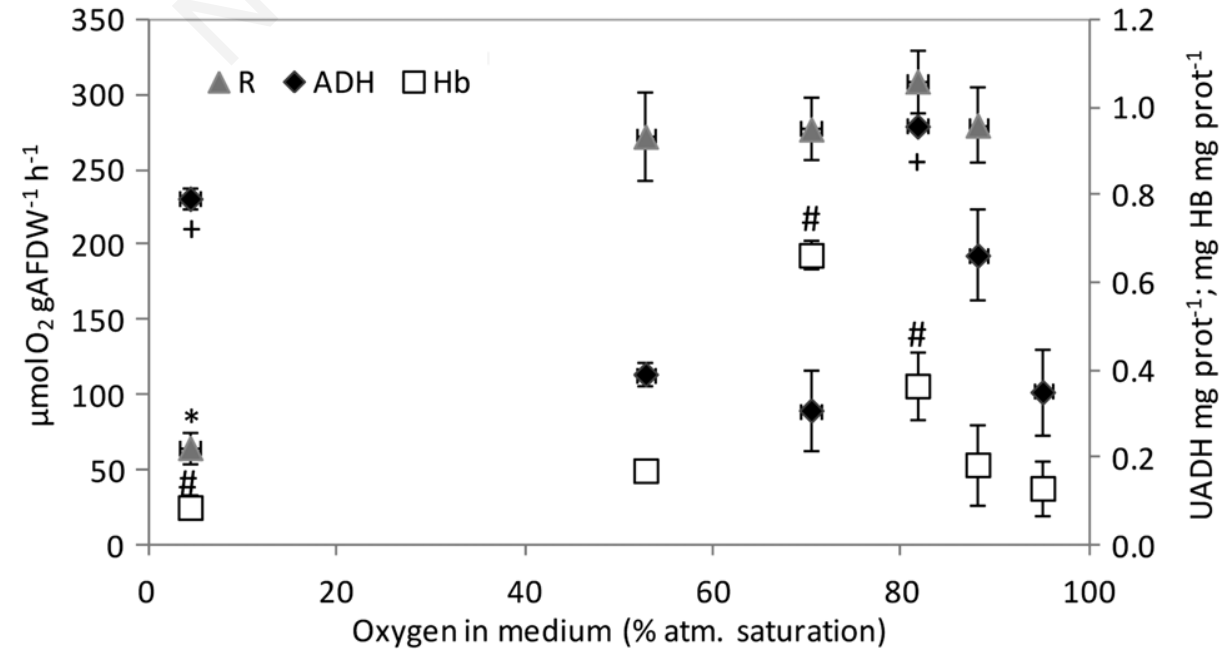

Fig. 1. Trend of ADH activity, Hb amount and oxygen consumption (R) (mean $\pm \mathrm{SE}$ ) in larvae exposed to progressive hypoxia. Statistically significant differences compared to control value (time zero) for: * $\mathrm{R}$; $\mathrm{H} \mathrm{Hb} ;+\mathrm{ADH}$. 
time, its amount decreased to values significantly lower than the control after 2 days $(\mathrm{P}<0.001)$ (Fig. 1).

$\mathrm{ADH}$ activity increased progressively within the first $14 \mathrm{~h}(\mathrm{P}=0.03)$, when we recorded the maximum value $\left(0.958 \pm 0.001 \mathrm{UADH} \mathrm{mg} \operatorname{prot}^{-1}\right)$. The enzyme activity significantly decreased in the following $4-10 \mathrm{~h}(\mathrm{P}=0.044$ at $18 \mathrm{~h}$ ), but a significantly higher value, comparable with that measured at $14 \mathrm{~h}$, was recorded after $48 \mathrm{~h}$ of treatment $(\mathrm{P}=0.02)$.

The respiration rate $(\mathrm{R})$ increased slightly $(\mathrm{P}=0.06)$ within the first $14 \mathrm{~h}$ of treatment, reaching values of $309 \pm 20 \mu \mathrm{molO}_{2}$ gAFDW $^{-1} \mathrm{~h}^{-1}$ at $81.7 \%$ of oxygen saturation, but remained $>270 \mu \mathrm{molO}_{2}$ gAFDW $^{-1} \mathrm{~h}^{-1}$ within values of oxygen saturation $>50 \%$ (Fig. 1). R significantly decreased $(\mathrm{P}=0.03)$ only after $48 \mathrm{~h}$ of treatment $(=<5 \%$ of oxygen saturation) reaching values $<100 \quad \mu \mathrm{molO}_{2}$ gAFDW $^{-1} \mathrm{~h}^{-1}$.

\section{Anoxia incubation}

Survival was $100 \%$ until $48 \mathrm{~h}$ when $25 \%$ of treated larvae died.

Larvae exhibited undulating movements within the first $10 \mathrm{~min}$ of incubation, then they stopped any movements and became immobile.

The total amount of hemoglobin increased significantly $(\mathrm{P}=0.04)$ in the first $10 \mathrm{~h}$ of incubation from 0.155 to $0.595 \mathrm{mg} \mathrm{Hb} \mathrm{mg} \mathrm{prot}{ }^{-1}$, then rapidly decreased $(\mathrm{P}<0.001)$ remaining on values ranging between 0.285 and 0.176 , without significant differences between the four treatments (Fig. 2).

ADH activity significantly $(\mathrm{P}<0.001)$ increased in the first $14 \mathrm{~h}$ reaching its maximum value $(2.028 \pm 0.152$
UADH mg prot $\left.^{-1}\right)$, then rapidly decreased $(\mathrm{P}<0.001)$ to values comparable with the control, and never increased later on even if the treatment continued (Fig. 2).

\section{DISCUSSION}

Considering the worldwide distribution of Chironomus larvae and their potential as sentinel organisms in environmental monitoring (Choi et al., 1998), information about changes in their physiological condition and energy metabolism by natural stressors (i.e. physical stress or toxicants) seem to be relevant (Choi et al., 2001). Chironomus riparius is known to have an extraordinary adaptation capability due to the ability to shift to anaerobic metabolism when necessary, but also to keep activate aerobic metabolic pathways. As a consequence, this species can adapt quickly to the changing environmental conditions frequent in inland waters (Frank, 1983). Our data support these considerations. In C. riparius larvae we treated, hypoxia and anoxia induce hemoglobin synthesis and alter the specific activity of enzyme involved in carbohydrate catabolism such as alcohol-dehydrogenase. This means that in larvae exposed to decreasing oxygenation, the glycogen degradation is activated after the depletion of oxygen stored in $\mathrm{Hb}$.

The trends observed for $\mathrm{Hb}$ and $\mathrm{ADH}$ under progressive hypoxia suggest in fact that $\mathrm{Hb}$ might function as short-term oxygen storage, enabling animals to retard the on-set of anaerobiosis, and that alcoholic fermentation is for a short time (14-24 $\mathrm{h}$ of incubation, about $84-53 \%$ of oxygen saturation) co-occurring, becoming the prevalent metabolic pathway at oxygen percentage lower than 5\% $\left(<1 \mathrm{mg} \mathrm{L}^{-1}\right)$. Other authors reported evidences that larvae

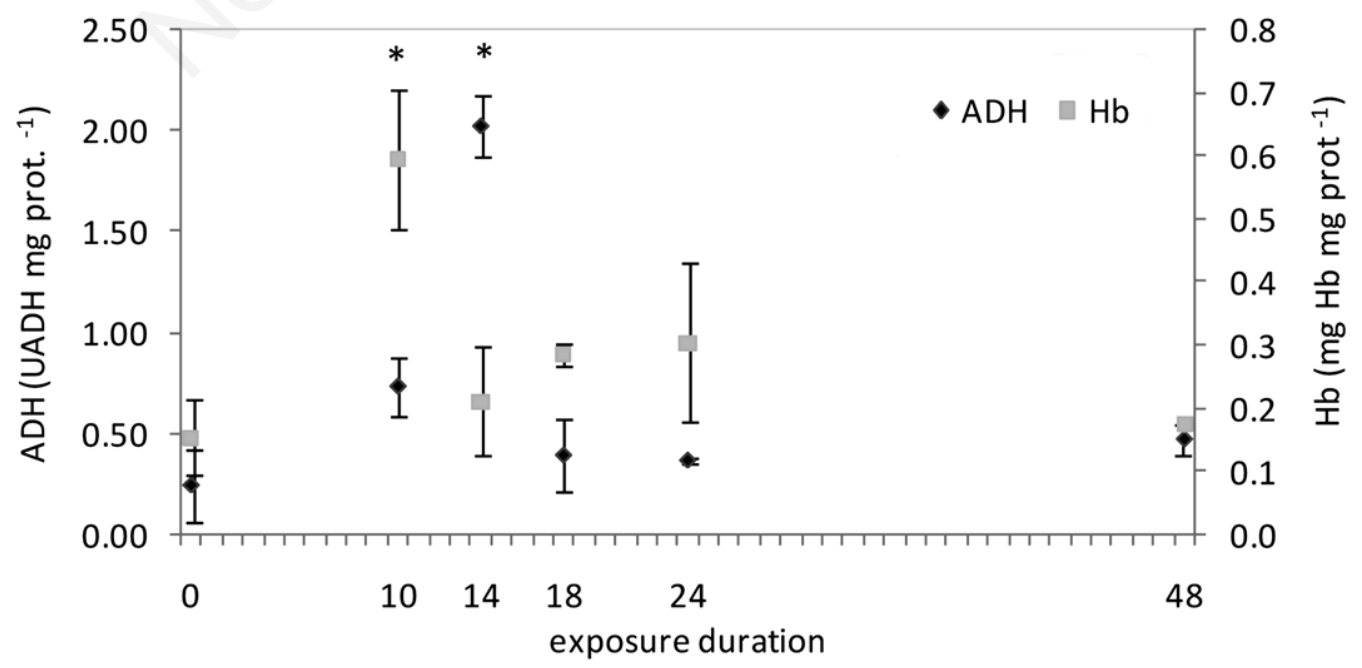

Fig. 2. $\mathrm{ADH}$ activity and $\mathrm{Hb}$ amount $(\mathrm{mean} \pm \mathrm{SE})$ in larvae exposed to anoxia. * Statistically significant differences compared to control value (time zero). 
of $C$. riparius can virtually maintain their normal respiratory rate until the oxygen content of the water reaches a critical limit at approximately $1 \mathrm{mgL}^{-1}\left(\mathrm{pO}_{2}=15\right.$ Torr), switching to anaerobic processes when oxygen content declines below $0.7 \mathrm{mgL}^{-1}$ (Redecker and Zebe, 1988; Zebe, 1991). Jónasson (1978) reported as critical limit for aerobic respiration of $56 \%$ of oxygen saturation for larvae of C. plumosus.

Strong undulating body movements were observed only within the first $24 \mathrm{~h}$ of incubation to progressive hypoxia, the same kind of movements which are performed in natural conditions to irrigate their dwelling-tubes in the hypoxic mud to saturate the hemoglobin with oxygen (Hoback and Stanley, 2001). At this time of incubation, corresponding to an oxygen percentage of about $50 \%$, the first suffering and dead larvae were found due to hypoxia stress. We excluded that starvation could have been the cause of death, according to previous studies that reported lethal times of 205 e 100 days in anoxia without food supply at $4^{\circ} \mathrm{C}$ respectively for $C$. plumosus and $C$. anthracinus larvae (Nagell and Landahl, 1978).

The respiratory rate $(\mathrm{R})$ trend we measured is in accordance with that one observed by Hamburger et al. (1994) and Brodersen et al. (2008) in other Chironomini such as $C$. anthracinus, $C$. riparius and $C$. hyperboreus Staeger 1845 . Nevertheless a slight (not significant) increase in the first hours of treatment resembling typical a oxy-stressor, $\mathrm{R}$ remained constant within the first $24 \mathrm{~h}$ of treatment with a significant decrease only below $50 \%$ of oxygen saturation suggesting for $C$. riparius larvae from the Rio Gola a oxy-regulator behaviour (i.e., it regulates and maintains a constant $\mathrm{R}$ within a $\%$ saturation interval) (Brodersen et al., 2008). This trend demonstrates also the efficiency of chironomid $\mathrm{Hb}$ to capture oxygen from water (Brodersen et al., 2008). Only R measured after 48 $\mathrm{h}$ of incubation $\left(=65 \mu \mathrm{molO}_{2} \mathrm{gAFDW}^{-1} \mathrm{~h}^{-1}\right)$ was lower than $100 \mu \mathrm{molO}_{2} \mathrm{gAFDW}^{-1} \mathrm{~h}^{-1}$, as stated by Brodersen et al. (2008) for large chironomid larvae (Chironomus, Stictochironomus and Procladius) exposed for short periods of time ( $1 \mathrm{~h}$ ) to progressive hypoxia. Conversely we found higher values of $\mathrm{R}$ after shorter expositions (e.g., 309 $\mu_{\mathrm{molO}} \mathrm{gAFDW}^{-1} \mathrm{~h}^{-1}$ after $14 \mathrm{~h}$ ) comparable with those measured for smaller chironomid larvae such as Micropsectra described as oxy-stressor by Brodersen et al. (2008). The high oxygen consumption values we detected might also be associated to mud removing which occurred during the experiments (this is considering a strong stress for such tube-dwelling larvae; Jónasson, 1978).

In anoxic incubation experiments, metabolic adaptations occurred during the two days of treatments and alterations of biochemical parameters were evident after a few hours of anoxia exposure (larvae were found suffering just after few minutes of incubation). In these conditions, $\mathrm{Hb}$ and $\mathrm{ADH}$ both increased, reaching maximum value after 10 and $14 \mathrm{~h}$ of treatment respectively. After that, both decreased approximately to the values of the control. This trend was observed previously by Frank (1983) in C. plumosus where larvae tried to maintain as long as possible the aerobic metabolism even at oxygenation was constantly lower than $5 \%\left(<0.5 \mathrm{mg} \mathrm{L}^{-1}\right)$ as in our case. It has been calculated that in such conditions as much as $80 \%$ of the energy demand of $C$. plumosus gr. larvae is covered by the alcoholic fermentation of glycogen stores to ethanol (Scholz and Zerbst-Boroffka, 1998). Hamburger et al. (1994) reported that anaerobic metabolism represents from 3 (at $3 \mathrm{mgO}_{2} \mathrm{~L}^{-1}$ ) to $40 \%$ (at 0.5 $\mathrm{mgO}_{2} \mathrm{~L}^{-1}$ ) of total energy production in Chironomus larvae $(C$. anthracinus can regulate its respiratory metabolism down to 2-3 $\mathrm{mgO}_{2} \mathrm{~L}^{-1}$ ). Choi et al. (2001) reported that at $1.6 \mathrm{mgO}_{2} \mathrm{~L}^{-1}$ a switch from aerobic to partial anaerobic metabolism occurred after $48 \mathrm{~h}$ of treatment. The trend we observed for ADH activity is comparable with findings by Forcella et al. (2007) in C. riparius and by Frank (1983) in C. plumosus IV-instar larvae maintained in anoxic conditions by $\mathrm{N}_{2}$ insufflations. On the other hand, we measured higher values of enzyme activity (of about $57 \%$ ) after the same time of exposure respect to Forcella et al. (2007) (about $1400 \mathrm{nmol} \mathrm{min} \mathrm{mg}^{-1} \mathrm{mrot}^{-1} \mathrm{~h}$ in Forcella et al. (2007), $2637 \mu \mathrm{mol} \mathrm{g} \mathrm{dw}{ }^{-1} \mathrm{~h}^{-1}$ our result after $24 \mathrm{~h}$ ) but similar to the ADH activity values reported by Frank (1983) $\left(7127 \mu \mathrm{mol} \mathrm{g} \mathrm{dw}^{-1} \mathrm{~h}^{-1}\right.$ in Frank (1983) and $8163 \mu \mathrm{mol} \mathrm{g} \mathrm{dw} \mathrm{g} \mathrm{h}^{-1}$ our result after $48 \mathrm{~h}$ ). In anoxia conditions, larvae activated immediately strong undulating movements for few minutes then they stop their irrigating activity. This behavioural reaction was observed also by Walshe (1951) in C. riparius larvae exposed to less than $7 \%$ of oxygenation: they stopped almost immediately to irrigate the tubes and their hemoglobin resulted partly deoxygenated. After two days of incubation at $<1 \%$ of oxygen saturation, some larvae were found dead. Such oxygenation level are probably too low for $C$. riparius, that typically inhabit running waters polluted by sewage where oxygen saturation might be even approximately to $100 \%$ due to water turbulence (Frank, 1983) (in our case, the oxygen saturation of Rio Gola was 103\%). In fact, within the genus Chironomus, $C$. riparius is not the most resistant species to low oxygen content. Specifically, Frank (1983) reported the following order to resistance: C. plumosus $>$ C. anthracinus $>$ C. tentans Fabricius 1805 $>C$. riparius $>C$. piger Strenzke 1956. Our data give new insight on autoecology of such species, confirming that anoxia represents anyway a stress condition to which physiological compensatory mechanisms are activated.

\section{CONCLUSIONS}

In accordance with findings and hypotheses tested in numerous previous studies (e.g., Hervant et al., 1996; Choi et al., 2001; Hermes-Lima and Zenteno-Savín, 2002; 
Ha and Choi, 2008), we confirm that IV-instar larvae of C. riparius can withstand hypoxic and anoxic conditions and that they undergo compensatory adjustments in the energy metabolism to maintain, in such conditions, physiological or biochemical functions at a normal (i.e., homeostatic) level, switching from aerobic to anaerobic pathways (consumption of energy-yielding substrates, e.g., glycogen). Notwithstanding $\mathrm{Hg}$ amount and ADH activity we measured did not respond linearly with the oxygen concentrations or the period of anoxia, $\mathrm{Hb}$ and $\mathrm{ADH}$ might be proposed as candidate biomarkers for the environmental monitoring of running waters even as alternative to the analyses of anaerobic end products to determine the anaerobic metabolism in chironomid larvae (Fields, 1983). The use of molecular endpoints (as done in an oriental river prawn by Sun et al., 2014) might support these conclusions and clarify for example if the apparent changes in ADH activity are due to changes in expression of genes encoding the enzyme or are due to changes in existing ADH enzyme, giving more insights on such metabolites and their role in survive anoxia/hypoxia in aquatic insects.

\section{ACKNOWLEDGEMENTS}

The Authors thank: Matilde Forcella for her help in laboratory experiments at the University of Milan - Bicocca; Alessandra Franceschini (MUSE-Science Museum of Trento) for field sampling assistance and for aquarium managing; Victor Alekseev (Russian Academy of Science, San Petersburg) for his suggestions to set up the protocol of oxygen consumption measurement; two anonymous reviewers for their useful comments that improved the manuscript. The research was supported by the Ph.D. grant of the first Author by the University of Milan and by the MUSE- Science Museum of Trento.

\section{REFERENCES}

Armitage P, Cranston PS, Pinder LCV, 1995. Chironomidae: biology and ecology of non-biting midges. Chapman and Hall, New York: 584 pp.

Bergtrom G, Laufer H, Rogers R, 1976. Fat body: a site of hemoglobin synthesis in Chironomus thummi (Diptera). J. Cell. Biol. 69:264-274.

Bradford MM, 1976. A rapid and sensitive method for the quantitation of microgram quantities of protein utilizing the principle of protein-dye binding. Anal. Biochem. 72:248-254.

Brodersen KP, Pedersen O, Walker IR, Jensen MT, 2008. Respiration on midges (Diptera: Chironomidae) in British Columbian lakes: oxy-regulation, temperature and their role as paleo-indicators. Freshwater Biol. 53:593-602.

Choi J, 2004. Biomarkers in environmental monitoring and its application in Chironomus spp., p. 203-215. In: S-K. Hong, J.L. Lee, B-S. Ihm, A. Farina, Y. Son, E-S. Kim and J.C. Choe (eds.), Ecological issues in a changing world - status, response and strategy. Kluwer Academic Publ.
Choi J, Rivoal F, Roche H, Caquet T, 1998. [Identification de biomarqueurs d'écotoxicité chez deux organisms sentinelles potentiels, le chironome (Chironomus riparius $(\mathrm{Mg})$ ) et la lymnee (Lymnea palustris (Muller))].[Article in French]. Ichtyophysiologica Acta 21:89-106.

Choi J, Roche H, 2004. Effect of potassium dichromate and fenitrothion on hemoglobins of Chironomus riparius $\mathrm{Mg}$. (Diptera, Chironomidae) larvae: potential biomarker of environmental monitoring. Environ. Monit. Assess. 92: 229-239.

Choi J, Roche H, Caquet T, 2000. Effects of physical (hypoxia, hyperoxia) and chemical (potassium dichromate, fenitrothion) stress on antioxidant enzyme activities in Chironomus riparius $\mathrm{Mg}$. (Diptera, Chironomidae) larvae: potential biomarkers. Environ. Monit. Assess. 19:495-500.

Choi J, Roche H, Caquet T, 2001. Hypoxia, hyperoxia and exposure to potassium dichromate or fenitrohion alter the energy metabolism in Chironomus riparius Mg. (Diptera: Chironomidae) larvae. Comp. Biochem. Phys. C 130:11-17.

Fields JHA, 1983. Alternatives to lactic acid: possible advantages. J. Exp. Biol. 228:445-457.

Forcella M, Berra E, Giacchini R, Hanozet GM, Parenti P, 2004. Changes in leucine transport activity in Chironomus riparius larvae after short-term exposure to potassium dichromate and fenitrothion. Arch. Insect Biochem. Physiol. 55:90-10.

Forcella M, Berra E, Giacchini R, Parenti P, 2007. Antioxidant defenses preserve membrane transport activity in Chironomus riparius larvae exposed to anoxia. Arch. Insect Biochem. Physiol. 65:181-194.

Frank C, 1983. Ecology, production and anaerobic metabolism of Chironomus plumosus L. larvae in a shallow lake. Arch. Hydrobiol. 96:354-362.

Ha M-H, Choi J, 2008. Effects of environmental contaminants on hemoglobin of larvae of aquatic midge, Chironomus riparius (Diptera: Chironomidae): a potential biomarker for ecotoxicity monitoring. Chemosphere 71:1928-1936.

Hamburger K, Dall PC, 1990. The respiration of common benthic invertebrate species from the shallow littoral zone of Lake Esrom, Denmark. Hydrobiologia 199:117-130.

Hamburger K, Lindegaard C, Dall PC, 1994. Energy metabolism of Chironomus anthracinus (Chironomidae, Diptera) from the profundal zone of Lake Esrom, Denmark, as a function of body size, temperature and oxygen concentration. Hydrobiologia 294:43-50.

Hanozet GM, Simonetta M, Gerola G, 1976. Activation of rat liver alcohol dehydrogenase by deoxycholic acid. FEBS Lett. 65:120-122.

Hermes-Lima M, Zenteno-Savin T, 2002. Animal response to drastic changes in oxygen availability and physiological oxidative stress. Comp. Biochem. Phys. C 133:537-556.

Hervant F, Mathieu J, Garin D, Freminet A, 1996. Behavioral, ventilatory, and metabolic responses of the hypogean amphipod Niphargus virei and the epigean isopod Asellus aquaticus to severe hypoxia and subsequent recovery. Physiol. Zool. 69:1277-1300.

Hoback WW, Stanley DW, 2001. Insects in hypoxia. J. Insect Physiol. 47:533-542.

Ingersoll CG, Nelson MK, 1990. Testing sediment toxicity with Hyalella azteca (Amphipoda) and Chironomus riparius (Diptera), p. 93-109. In: W.G. Landis and W.W. van der 
Schalie (eds.), Aquatic toxicology and risk assessment. 13. American Society for Testing and Materials, Philadelphia.

Int Panis L, Goddeeris B, Verheyen R, 1995. The hemoglobine concentration of Chironomus cf. plumosus L. (Diptera: Chironomidae) larvae from two lentic habitats. Neth. J. Aquat. Ecol. 29:1-4.

Jónasson PM, 1978. Edgardo Baldi memorial lecture - Zoobenthos of lakes. Verh. Internat. Verein Limnol. 20:13-37.

Lampert W, 1984. The measurement of respiration, p. 413-468. In: J.A. Downing and F.H. Rigler (eds.), A manual on methods for the assessment of secondary productivity in fresh waters. 17. Blackwell Scientific Publ., Oxford.

Layne E, 1957. Spectrophotometric and turbidimetric methods for proteins, p. 447-454. In: S. Colowick and N.O. Kaplan (eds.), Methods in Enzymology. 3. Academic Press, New York.

Lee S-E, Dong-hun Y, Son J, Cho K, 2006. Proteomic evaluation of cadmium toxicity on the midge Chironomus riparius Meigen larvae. Proteomics 6:945-957.

Lencioni V, Bernabo P, Vanin S, Di Muro P, Beltramini M, 2008. Respiration rate and oxy-regulatory capacity in cold stenothermal chironomids. J. Insect Physiol. 54:1337-1342.

Lindegaard C, 1995. Classification of water-bodies and pollution, p. 385-404. In: P. Armitage, P.S. Cranston and L.C.V. Pinder (eds.), Chironomidae: biology and ecology of nonbiting midges. Chapman and Hall, New York.

Marsh AG, Manahan DT, 1999. A method for accurate measurements of the respiration rates of marine invertebrate embryos and larvae. Mar. Ecol.-Prog. Ser. 184:1-10.

Marziali L, Lencioni V, Rossaro B, 2006. Adaptation of pupae of Chironomidae (Insecta: Diptera) to oxygen-poor habitats. Pol. J. Ecol. 54:687-693.

McCauley J, 1974. Instar differentiation in larval Chironomidae (Diptera). Can. Entomol. 106:179 -200.

Nagell B, Landahl CC, 1978. Resistance to anoxia of Chironomus plumosus and Chironomus anthracinus (Diptera) larvae. Holarct. Ecol. 1:333-336.

Osmulski PA, Leyko W, 1986. Structure, function and physiological role of Chironomus haemoglobin. Comp. Biochem. Phys. B 85:701-722.

Penttinen O-P, Holopainen IJ, 1995. Physiological energetics of a midge, Chironomus riparius Meigen (Insecta, Diptera): normoxic heat output over the whole life cycle and response of larva to hypoxia and anoxia. Oecologia 103:419-424.

Redecker B, Zebe E, 1988. Anaerobic metabolism in aquatic insect larvae: studies on Chironomus thummi and Culex pipiens. J. Comp. Physiol. B 158:307-315.
Rosenberg DM, 2005. Freshwater biomonitoring and Chironomidae. Aquat. Ecol. 26:101-122.

Rossaro B, Solimini A, Lencioni V, Marziali L, Giacchini R, Parenti P, 2007. The relationship between body size, pupal thoracic horn development and dissolved oxygen in Chironomini (Diptera: Chironomidae). Fundam. Appl. Limnol. 169:331-339.

Sæther OA, 1979. Chironomid communities as water quality indicators. Holarct. Ecol. 2:65-74.

Scholz F, Zerbst-Boroffka I, 1998. Environmental hypoxia affects osmotic and ionic regulation in freshwater midge-larvae. J. Insect Physiol. 44: 427-436.

StatSoft, 2012. STATISTICA (data analysis software system), ver. 12.0. Available from: www.statsoft.com

Sun S, Xuan F, Ge X, Fu H, Zhu J, Zhang S, 2014. Identification of differentially expressed genes in hepatopancreas of oriental river prawn, Macrobrachium nipponense exposed to environmental hypoxia. Gene 534:298-306.

Tentori L, Salvati A, 1981. Hemoglobinometry in human blood, p. 707-715. In: E. Antonini, L. Rossi-Bernardi and E. Chiancone (eds.), Methods in enzymology. 76. Hemoglobins. Academic Press, New York.

Walshe B, 1951. Haemoglobin and filter feeding, Chironomus (Diptera). J. Exp. Biol. 28:57-61.

Weber RE, 1980. Functions of invertebrate Hemoglobins with special reference to adaptations to environmental hypoxia. Am. Zool. 20:79-101.

Weber RE, Braunitzer G, Kleinschmidt T, 1985. Functional multiplicity and structural correlations in the Hemoglobin system of larvae of Chironomus thummi thummi (Insecta, Diptera): hemoglobin components CTT I, CTT II beta, CTT III, CTT IV, CTT VI, CTT VIIB, CTT IX and CTT X. Comp. Biochem. Phys. B 80:747-753.

Weber RE, Vinogradov SN, 2001. Non-vertebrate hemoglobins: Function and molecular adaptation. Physiol. Rev. 81:569628.

Wilps H, Schöttler U, 1980. In vitro-studies on the anaerobic formation of ethanol by the larvae of Chironomus thummi thummi (Diptera). Comp. Biochem. Physiol. B Biochem. Mol. Biol. 67:239-242.

Winkler LW, 1888. [Die Bestimmung des im Wasser gelösten Sauerstoffes].[Article in German]. Ber. Dtsch. Chem. Ges. 21:2843-2855.

Zebe E, 1991. In vivo studies on the function of hemoglobin in the larvae of Chironomus thummi (Insect, Diptera). Comp. Biochem. Physiol. 99:525-529. 